\title{
Plating manifesto (II): the art and science of plating
}

\author{
Charles Spence $^{1 *}$, Betina Piqueras-Fiszman ${ }^{1}$, Charles Michel ${ }^{1}$ and Ophelia Deroy ${ }^{2}$
}

\begin{abstract}
It is well known that people serve themselves more, not to mention eat more, when dining from larger bowls and plates than from smaller ones. But what about the other visual qualities of the plateware? Does the colour, shape and finish also influence a diner's behaviour? How important are these extrinsic visual properties, or even the visual arrangement of the elements on the plate itself, in terms of modulating a diner's eating behaviours and experiences? At a time when so much is known about the influence of the colour of individual food products on taste and flavour perception, and when so many modernist restaurants are using an increasingly eclectic range of visual designs for their dishes, there has been surprisingly little scientific research on how the more complex visual properties and arrangement of food presentations may affect the diner. Below, we argue that the exploration of these effects constitutes the next natural step in an increasingly fruitful interdisciplinary collaboration between chefs, psychologists, sensory scientists and designers. The most important research questions, then, are to identify the kinds of effects that the presentation style has on the multisensory consumption experiences and behaviours of diners, and to study the interactions between the different visual cues that are provided. Taken together, the evidence reviewed here helps to emphasize the fact that getting both the plateware and the plating right constitute surprisingly important components to sublimate the flavours of the food, in the delivery and experience of a great meal.
\end{abstract}

Keywords: Colour, Eating behaviour, Expectations, Flavour, Plating, Shape, Vision

"And as flavours are under constant refinement, [cooking] is perpetually improving to satisfy them. (...) it will become more scientific and more specific." Auguste Escoffier, in 1902 [1].

\section{Background}

Much of the earlier research on the visual presentation of food was conducted with quantities and specific health concerns in mind, focusing on how the size of the plate might influence how much people would serve themselves, and how much they would eventually consume. It is only recently that scientists - sometimes in collaboration with chefs - have started to look at the more perceptual and hedonic effects of the visual properties of the plateware, such as its colour, shape and size.

Choosing the right format of plate for a specific dish can be very important. For instance, the food should not

\footnotetext{
* Correspondence: charles.spence@psy.ox.ac.uk

${ }^{1}$ Crossmodal Research Laboratory, Department of Experimental Psychology, University of Oxford, South Parks Road, Oxford OX1 3UD, England, UK

Full list of author information is available at the end of the article
}

appear too crowded, but should instead convey the notion that the portion size is adequate and not too measly. Many other such principles might apply, which need to be investigated. The importance of conducting research on complex food presentations and to include plateware is all the more important nowadays as restaurant experience is taking on an increasingly aesthetic character, as we stressed in Part 1 of this manifesto. It is also important to note here that research in this area remains relevant to the health concerns that guided many of the initial studies conducted on portion size, given the recent stress on mindful eating, and on the quality of the experience present in dietetic guidelines.

Crucially, the focus here on the effects of the complex visual presentation of dishes of food will hopefully lead to a better understanding of the highly diverse, and culturally rich, practices that surround the human consumption of food. Several studies, including a growing number of neuroimaging experiments, have highlighted the importance of vision for our food behaviours (see [2], for a review), and have stressed the primary importance of vision when it comes to the selection of food. Researchers have also
C Biomed Central 
demonstrated how the sight of food elicits anticipatory physiological responses, such as salivation, changes in heart rate and insulin levels [3-5], and emotional responses such as a desire to eat [6], as well as setting-up cognitive expectations linked to our previous experiences and familiarity with the food $[7,8]$. However, many of these results have been based on studies in which people lying in the brain scanner were shown pictures of edible versus inedible objects, and have little to say about the variations introduced by the appearance of foods themselves, let alone by their presentation. Will the same tart elicit a different neural response when presented on different coloured plates, or when presented in a different orientation? Will it elicit some aesthetic response in the viewer, and can this be independent of previous experiences with the food? These questions should open up a whole new range of studies designed to investigate the physiological, emotional and cognitive effects of these more fine-grained cues that are characteristic of our 'visually dominated' food behaviours; they should also enable psychophysical and neurological studies to come closer to what is happening in real-world environments.

Here, we wish to offer a review of the pioneering studies conducted in this area, which all converge to suggest variations in the visual presentation of food can indeed exert an effect on our eating experiences. As expected, when directing their attention to a culturally rich practice, psychologists need to be aware of the range and complexity of the underlying effects that may be at stake regarding plateware, as we stress in this review; scientists also need to be aware of the many layers of the object of their studies. Plating does not stop with the choice of plate, but extends to the complexity of the overall arrangement on the plate and the interactions between the various visual attributes of plateware. Background semantic and contextual aspects that are inevitably associated with specific foods, dishes or eating situations are also likely to introduce important variability. What all of these challenges and the available research clearly suggests, then, is that a proper understanding of plating and food presentation offers something of a formidable opportunity to articulate the insights of a varied range of disciplines and fields of research, and to test them in the laboratory as well as in the restaurant setting.

\section{Review}

\section{The plate as a variable}

\section{On the size of the plate}

It is now well known, at least by psychologists, that diners are influenced by the size of the plateware, mostly when it comes to calculating how much food to serve themselves and/or how much they eventually consume [9]. Since early in the last century the average size of plates has increased by around 20\% [10], as has the average waist size of humans [11]. In one influential study, Wansink et al. [12] investigated the effect of the size of the bowl on people's food consumption at a social event. When the participants in this study were given a larger bowl to eat from, they served themselves over 50\% more ice cream than those given a much smaller bowl. Furthermore, since the participants nearly always finished their food (as is apparently generally the case under self-serve conditions $[13,14]$ ), those eating from a larger bowl ended up consuming far more ice cream overall ${ }^{\mathrm{a}}$.

Van Kleef et al. [15] obtained similar results when the bowls that differed in size were the everyday containers from which a pasta dish was served in the setting of a canteen. In this case, the difference in capacity was nearly double (3.8 versus 6.8 L). Despite the fact that the diners' individual plates were all of the same size (approximately $23 \mathrm{~cm}$ in diameter), those who served themselves from the larger communal bowl ended up with $77 \%$ more pasta and (perhaps unsurprisingly) felt more satiated than those serving themselves from the smaller communal bowl.

Wansink and colleagues attempted to account for these results in terms of the Ebbinghaus-Titchener size-contrast illusion and/or the Delboeuf illusion [16,17]. In perhaps the most well-known version of the former illusion, a circle appears larger when surrounded by smaller circles than another identical circle surrounded by bigger circles (see Figure 1A). The latter illusion makes one think that, of two identical circles, the one that happens to be surrounded by a larger ring will look smaller than the other one without a ring or else surrounded by a smaller ring (see Figure 1B). Wansink and colleagues suggested that such visual illusions may have caused a given amount of food to be perceived as much smaller against the background of a larger bowl, and as larger when presented in a smaller bowl instead [14].

It is important to note that the effects of the size of the plate on a diner's consumption behaviour are somewhat inconsistent. For instance, Rolls et al. [18] were unable to find a significant difference between the diameter of the plate $(17,22$ or $26 \mathrm{~cm})$ and the amount of food that was consumed at a meal in three separate laboratory-based studies. Remember here that Rolls et al. tested consumption behaviour in the laboratory, whereas Wansink et al. had their participants fill out questionnaires at a company picnic (that is, at a real-world event), so the discrepancy between the significant results reported by Wansink et al. [12] and the null results reported by Rolls et al. may point to the existence of important differences between people's food consumption behaviours when tested in the laboratory and those seen under more realistic dining conditions [19]. Such differences should certainly always be kept in mind when trying to generalize from the results of laboratory-based psychological research through to predicting people's real-world eating behaviours [20]. 
A

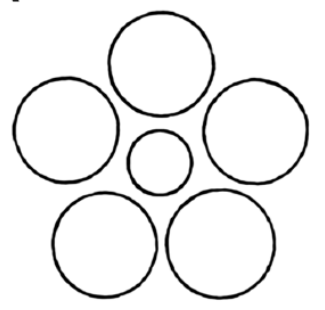

B

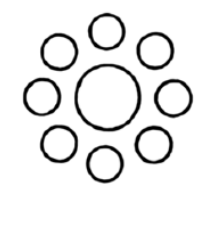

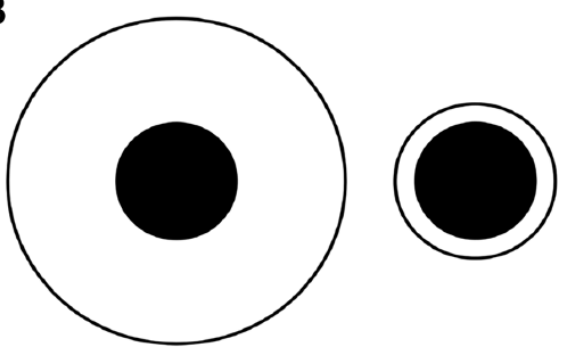

Figure 1 Representations of the (A) Ebbinghaus-Titchener size-contrast illusion and (B) Delboeuf illusion.

Portion size has mostly been interesting because of its relevance for people's health, specifically in relation to various quantitative approaches to eating. For example, Rozin et al. [21] explained that one of the main reasons for the so-called 'French paradox' stemmed from differences in portion size between France and the US. The French remain slimmer than their North American counterparts, and have a lower mortality rate from heart disease, despite the fact that they eat meals containing a higher proportion of saturated fat and consume less fatreduced foods than do Americans. The reason for this is apparently that, in France, portion sizes are much smaller in full-service restaurants, buffets and supermarkets. The same is apparently also true if one looks at estimated portion sizes based upon the recipes found in cookbooks in the two countries.

These portion size studies have likely biased the direction of subsequent research in a way that should perhaps be corrected. The focus on quantities consumed notably leaves out other aspects of the eating experience, including some that might be relevant in terms of health. Could it not be the case that aesthetically arranged smaller food portions lead to more mindful and considered eating? And might that not be expected to have an influence on the perceived satiety, overall satisfaction and total food intake at meal times? It is our contention that these matters are definitely worth looking into (see [22] for a more general review of the effects of portion size). The focus on the illusory effects influencing the visual evaluation of quantities also leaves out the possible crossmodal effects that can affect flavour perception, or other aspects of the experience. These two missed elements are what we wish to explore below.

\section{On the colour of the plate}

Many chefs and cooks alike use white plates to showcase their culinary offerings, though black is sometimes used too. There are, of course, many other colours as well for anyone who wants to spend their time perusing the pages of the catering catalogues or the shelves of the kitchen stores. In his restaurant, Denis Martin [23] uses charger plates (large flat dishes, placed under one's normal plate, that are used primarily for decorative purposes) presented in the primary colours (blue, red and green, a different coloured plate for each diner) as the base on which to place the different white dishes on which the food will actually be served. Pushing the quest for the right colour even further, and echoing the use of plates as canvasses evoked in our previous paper [24], modernist chefs like Sebastien Lepinoy (Executive Chef at L'Atelier de Joel Robuchon) have noted that, 'Colour is important, so instead of having boring white plates, we have a chef that comes in every morning to paint the plates to match the dishes on the menu. The dishes must catch the attention of the guest at first sight. It must entice the appetite' [25]. But where does this power to entice come from - and which part of it has to do with the coloured plate?

Until recently, all there was in terms of the choice of coloured plates were intuitions and untested rules. Some, like Lyman in his 1989 book on the psychology of food [16], suggested, for instance, that purple grapes do not look quite right when served from a blue plate. Other popular beliefs include the notion that, 'The color brown is another dark color that tends to make people not feel very hungry. Brown reminds people of food that has been overdone or burnt. A few people might think of homemade bread or other baked goods when looking at the color brown, but for the most part this is a color not associated with an increase in one's appetite' [26]. It is, however, only over the last couple of years or so that such anecdotal claims have been assessed empirically (specifically that the colour of the plateware might exert a significant impact on the appetite or even the taste or flavour of whatever happens to be served from it).

For example, the participants in one laboratory study had to sample sweet or salty popcorn from four differently coloured bowls: white, blue, green and red [27] $]^{\mathrm{b}}$. The salty popcorn was rated as tasting significantly sweeter when taken from a blue or red bowl, while the sweet popcorn was rated as tasting saltier when taken from the blue bowl. Although these effects were pretty small (averaging only a $4 \%$ change in participants' responses for the food taken from the coloured bowl as 
compared to from the white bowl), they were nevertheless still statistically significant. In another study that took place in Ferran Adrià's Alícia Foundation, a culinary school and research institute situated near Barcelona, Spain, Piqueras-Fiszman et al. [28] compared the taste of a strawberry-flavoured mousse (of a homogenous texture and colour) that was served on either a black or a white plate. The dessert served from the white plate was perceived as being $15 \%$ more intense, $10 \%$ sweeter and was $10 \%$ more liked than exactly the same mousse when served from a black (otherwise identical) plate. In this case, the colour of the plate may have affected the perceived colour of the food by means of the well-known phenomenon of colour contrast. In the case of simultaneous colour contrast $[29,30]$, an object seen in the foreground appears to have a different colour (or contrast) depending on the colour of the background [31,32]. This explanation had already been offered intuitively by Lyman: 'Simultaneous color contrast suggests that foods can be arranged in combinations so that their colors are subtly enhanced, subdued, or otherwise modified. Yellow scrambled eggs on a yellow plate will look paler because of contrast. Purple grapes will look less purple on a purple plate and will look redder on a blue plate. A green salad will look less green on a green plate than on a plate that has no green in it. Red food on a blue plate will look more orange. Broccoli served with red fish will make the fish look redder, and slices of lime surrounding a grape mousse will enhance the color of both' ([16] p. 112).

Following this interpretation, the colour of the mousse served in Piqueras-Fiszman et al.'s study may have appeared more salient when set against the background of the white plate than when served from the black plate. Thus, the rated intensity of the food's taste (that is, its sweetness or saltiness) will presumably have been influenced by its perceived colour saturation, which, in turn, will have been influenced by the colour saturation of the plate itself. Another possibility, coming from the documented effects of colour saturation on smell intensity [33], is that the contrast improved the olfactory component of the food, and in this way affected the participants' overall flavour appreciation (see [34] for a review).

That said, colour contrast cannot so easily be used to explain the effects of coloured bowls reported by Harrar et al. [27]. One reason for this is that the popcorn in this study was eaten by hand and would therefore likely always have been seen against a background of a constant colour (the participant's hand) just before being placed in their mouth. However, an alternative possibility here is that the effects reported by Harrar et al. constitute an example of an effect known as 'sensation transference', whereby the attributes of a product perceived via one sensory modality can bias a consumer's appraisal of the qualities of another product as experienced in the same or different sensory modalities. The transference here would be attributable to the fact that red is typically associated with sweetness whereas blue is more often associated with saltiness [34-37]. The next question, then, is where exactly such colour-taste associations may originate from in the first place. We believe that the most likely explanation is that consumers are simply attuned to the natural statistics of the environment [36]; more importantly, perhaps, they can be attuned to the regularities in packaging and product colouring typically used in the supermarket [34,38,39].

More recently, Piqueras-Fiszman et al. [19] tested the extent to which the colour of the plateware (again, black and white plates were used) influenced the gustatory and hedonic experiences of a complex food (desserts with layers and decorations having different colours, textures, tastes and flavours). Importantly, this study was performed in an entirely naturalistic setting, the experimental restaurant at the Institut Paul Bocuse Research Centre, in Lyon, France, under conditions that were as ecologically valid as possible. The study used a between-participants experimental design, and the diners were able to interact and consume a three-course meal at their own pace. Over the course of this two-week study, three different desserts were served (see Figure 2). The results demonstrated that the colour of the plateware exerted a significant influence on people's perception of the food, but that this effect varied as a function of the type of dessert that was served.

Interestingly, the perceptual pattern for each dessert was constant for each plate used. For all of the attributes rated, including how appetizing the food was, its appearance, colour intensity, flavour intensity and the participants' overall liking, higher scores were obtained with the same plate, for each of the desserts. However, these results could not be accounted for solely in terms of contrast effects, because it was the dessert that had a darker brownish hue that participants rated more highly when served on the black plate (the other two desserts, which were red and creamy in colour, were rated as looking more delicious when served from the white plate). It could be that the desserts simply looked better (that is, more visually appealing) on a plate of a certain colour, and that this visual appraisal of the overall offering was what produced a halo effect on the other scores generated by the diners $[40,41]$. In conclusion, although explanations for the fact that the colour of the plate impacts taste and flavour perception have not yet been fully elucidated, the results of a growing number of laboratory and restaurant studies now demonstrate that the colour of the plate has more than a decorative role and could be chosen for more functional reasons ${ }^{c}$. It is our hope that such results will hopefully make innovative chefs, and those working in catering, think more carefully about the colour of their plateware and its potential effects on their customers' perception of taste and flavour. 


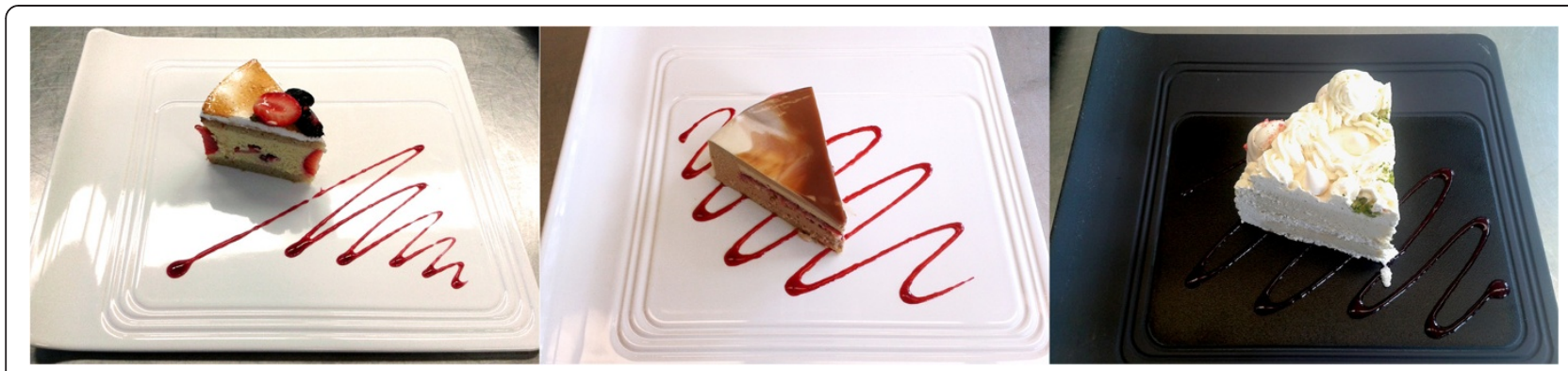

Figure 2 Desserts served on different coloured plates at the Institut Paul Bocuse Research Centre in the study by Piqueras-Fiszman et al. [19].

\section{On the shape of the plate}

Plates differ by more than one parameter. Besides colour, plates also present a variety of shapes. Certain restaurants use a wide range of eye-shaped, triangular and rectangular plates which they try to match to the food. Matching the shape of a plate to the dish may seem too fancy for many diners, and as yet there is surprisingly little research on the topic of the shape of the plateware on people's perception of the food that is served from it.

In one of the first studies to have provided results that are potentially relevant here, Gal et al. [42] reported that people (over 200 university students) rated cheese as tasting significantly sharper (by around 10\%) after having been made to stare at jagged shapes (as opposed to staring at rounded shapes. While it is important to bear in mind that such results come from a highly contrived laboratory study, they nevertheless hint at the potential impact that the angularity of the plateware might have on taste and flavour perception. Piqueras-Fiszman et al. [28] went on to investigate whether the shape of the plate itself might similarly influence people's taste/flavour perception (see Figure 3). However, these researchers failed to find any effect of the shape of the plateware on the taste of a strawberry-flavoured mousse. The plates used in their study were square, round and triangular. By contrast, Simner reported that eating food from a round versus star-shaped plate can exert a small but nonetheless significant effect on the perceived sharpness of the food (see also [43-45]).

So, what might explain the inconsistency in the results reported between these latter two studies? It would seem that the most likely explanation relates to the fact that Simner and colleagues used a star-shaped plate (with five points), whereas Piqueras-Fiszman et al. [28] used triangular and square plates (three and four points), with fairly rounded corners at that. Thus, the angularity of the plateware differed somewhat between these two studies. It may well be that really angular plateware is needed to emphasize the sharpness of the taste of a dish. Perhaps equally important, though, is the fact that the mousse in Piqueras-Fiszman et al.'s study was formed into an angular pyramid on the plate, and hence it is conceivable that the angularity of the food (seen in the foreground) may have overridden the angularity or roundness of the plate itself (which may have faded into the background of the diner's mind; see Figure 3). Such a contrast between the shape of the food and the shape of the plateware is a common feature of Japanese cuisine. According to Yang [25], 'When selecting tableware, a law of opposites is employed. If the food is round in shape, then a square or long, narrow flat dish is used.' Here it is certainly possible to wonder how shapes suggested during the eating experience (the plate or other items placed on the dining table) might be transferred to the sensory-discriminative terms that a diner uses to describe the food that they are eating [35]. That said, it should also be borne in mind that certain food attributes (such as their perceived sharpness, as in the case of cheese) may be more susceptible to being modified by the shape of the plate than are other attributes $[46,47]$. Remember that sharpness is fundamentally a tactile property. However, the term sharp is now used

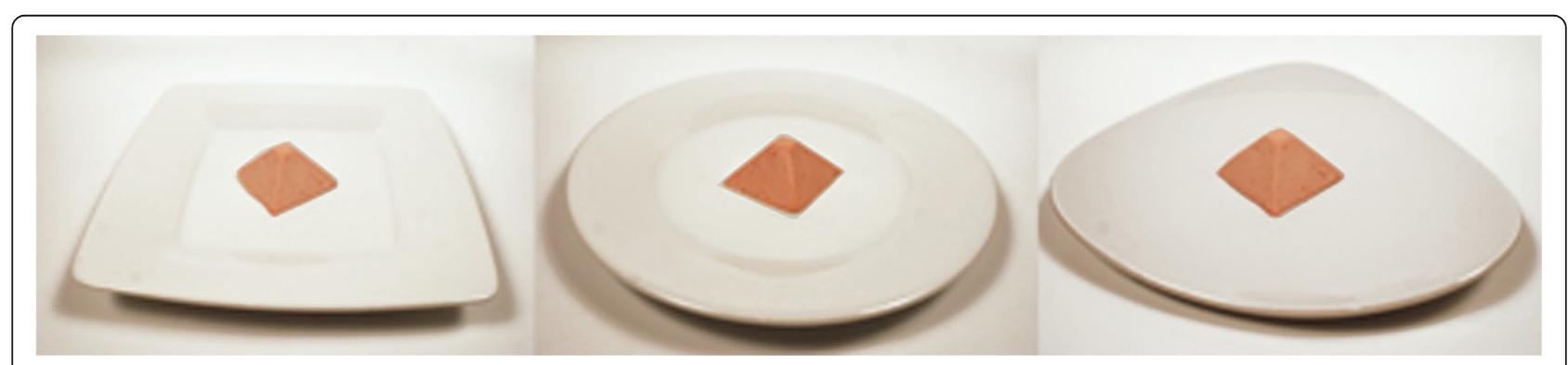

Figure 3 The strawberry-flavoured mousse served from square, round and triangular plates in the study by Piqueras-Fiszman et al. [28]. 
synaesthetically or crossmodally $[46,48]$ to describe certain taste or flavour attributes [49]. It is therefore possible that this term may be more likely to exhibit sensation transference effects when used to describe specific foodstuffs. According to this argument, taste terms that have primarily only ever been used to describe gustatory qualities (for example, saltiness) may be less susceptible to the effects of sensation transference from the shape qualities of the plateware.

\section{On the material and other properties of the plate}

The material properties of the plateware (or cutlery) bring additional cultural effects into the picture; certainly no one expects to eat from a porcelain plate in a fast-food joint or on an aircraft (unless a regular business-class traveller), just as no one would expect to be served from a plastic or paper plate in a smart restaurant. Silverware, although it is not a common material nowadays, has always been associated with high quality plateware, an association that we have from our ancestors. Back in the first century, in his book Cookery and Dining in Imperial Rome, Apicius suggested as a plating tip for his Apician Dish (number 141), 'an expensive silver platter would enhance the appearance of this dish materially' [50]. Today, a silver or gold finish charger plate might be used as part of the tableware and convey that touch of luxury and sophistication to the guests (although one does not tend to see them anymore, unless dining in a more traditional and elegant restaurant). But just what effect does serving on one plate or the other have on a diner's perception of the food? Although this is still a matter awaiting some serious scientific research, one can find some examples where a sense of luxury has been conveyed by means of shiny stainless steel sheets that have been thoughtfully shaped for elBulli [51]. We would not be surprised to find that the same food served on plastic plates, as compared to porcelain or metallic plates, would be perceived as being of lesser quality.

Besides cultural and semantic associations, the material properties of plates, and even more of cutlery, stress the need of a division between visual and non-visual properties. The expectations of different weights for plastic versus silver spoons, for instance, might already trigger the association between weight and quality noticed elsewhere [52,53]. This association between heaviness and importance or prestige, in turn, might be a 'metaphor we live by' [54]. Alternatively, it may rely on regularities picked up from the environment (namely that, at equal volume, heavier substances have a higher density and hence likely have a more nutritious content).

\section{Interim summary}

We have seen that the parameters of the conventional (traditional) plates, such as their size, shape, colour and material, have an important role in shaping our perception of the food, and on how much we serve ourselves, not to mention how much we eat. There is a growing body of laboratory-based research demonstrating the profound effect that plateware has, not only in terms of how much people enjoy that what they eat, but also on the sensory-discriminative attributes of the food. However, we might also point out here that, to date, only a few studies have ventured out into naturalistic settings (that is outside of the laboratory; see [19], for one of the few examples). Hence, it would be helpful to see more research being conducted in experimental restaurants, in arty pop-up venues, in cookery schools, and at the ever more popular class of 'science and gastronomy' events to help understand just how generalizable and robust some of these findings really are outside of a laboratory setting. Nevertheless, there is hopefully already enough evidence to convince the chef or adventurous home cook who believes that taste resides solely in the ingredients that he or she works with that there is much more to flavour, and to multisensory dining experiences, than simply what enters the mouth.

\section{Extending the complexity: from plate to plating}

Food presentation retains some characteristics of an art, mainly the complexity of the choices and dimensions involved behind the seemingly intuitive way in which the final result is obtained. In what follows, we consider several essential aspects to a proper understanding of the underlying complexity, and outline ways to study them experimentally.

\section{Choosing the right plate: size, colour, material and shape together}

While the studies reviewed in the last section have tended to vary a single attribute at a time (that is, the colour of the plate or the shape of the plate), in the future it will become increasingly important to vary a number of factors regarding the plateware at the same time to see how they interact. One step in this direction comes from a recent experiment conducted by Stewart and Goss [55]. They had their participants taste a cheesecake from a black or white plate that could be either round or square. The participants rated the dessert as $20 \%$ sweeter when tasted off the round white plate than off any of the other three plates. The effects of the plateware on flavour intensity were even more dramatic (30\% higher when served off the round white plate than when served from any of the other plates). Taken together, the results of several studies now support the conclusion that one of the best ways in which to keep the calorie count down while keeping our expectations fulfilled may well be to serve the food on a round white plate. 
Here one might ask what role habit plays in terms of the shape and colour of the plateware and its impact on the diner. Excepting some restaurant experiences, we mostly eat from round white plates. In this research, it seems possible that higher values might be given by diners to the foods presented on white (conventional) plates simply because that is the colour that most western diners will be more familiar with (note here the literature showing that familiarity very often breeds liking - as in the mere exposure effect [56]).

\section{Arranging food on the plate: on the visual composition of a dish}

Besides the support for the food (namely the plateware), it is important to consider how the food itself is placed on the plate. This is a topic that has seemingly been neglected by sensory scientists over the last few decades (for example, the topic does not merit a single mention in the more than 350 pages of Meiselman's volume Dimensions of the Meal [57]).

The various aspects of visual composition include, for example, the colour of the food or elements of the dish, the visual texture of the components and their combination (also important but little studied), the shape of the individual components, and the higher-order spatial arrangement of the various elements. Even the number of items on the plate (odd versus even) can potentially make a difference to a diner's impression of a dish. Up until very recently, however, no one had explored this topic in any detail. Researchers are now just beginning to conduct some intriguing studies that are starting to address the impact of the layout of the elements in a dish on people's responses to it. Interestingly, the framing of these experiments shows just how many different routes and hypotheses research can take when it comes to understanding the principles of plating.

For instance, Reisfelt et al. [58] investigated preferences for variations of a visually presented convenience meal among a large group of Danish consumers in a computer-based study carried out in Danish malls. These researchers used a discrete choice experimental design in which people were shown different series of eight photos, consisting of combinations of variations on a meal, defined in the following way: dish (modern or traditional); vegetables (root mix or wok mix); meat (slices or whole pieces of tenderloin pork); sauce (either present or absent); and herbs (dishes either with or without a parsley garnish). The respondents had to select the meal that they preferred, the dish they would choose second, and their least favourite dish. Perhaps the most relevant variable in the context of the present article is the first one. The modern dish was selected significantly more often than the traditional dish, with women preferring the modern variant more than the men. Additionally, a preference for the traditional version of the dish was positively correlated with age, with the elderly participants preferring this option more than the younger participants. These results seem to suggest that preferences for plating come from previous experience - and a possible comparison with the canonical or prototypical look of a certain dish. Here it would be interesting to understand how these prototypes are shaped, and the influence that semantic expectations have on the evaluation of the plated food coming to the table what counts as a good plating of a dish announced as, say, 'éclair au chocolat', might be different from what counts as a good plating for a dish made up of the same ingredients, but presented under a different name (for example, either one that might be familiar to the diner, like 'religieuse au chocolat', or else novel).

A different set of hypotheses can, however, be applied to plating, looking this time at more general aesthetic principles of harmony. Following the study of aesthetics for visual arts, the idea is that people's judgments or reactions are guided by general principles of visual harmony, which are variously analysed to include movement, unity, variety, balance, rhythm, emphasis, contrast, proportion and pattern [59-61]. The interest here for chefs is that these principles do not depend on background expectations set up by previous experiences with a dish, and explain why a novel arrangement appeals to consumers or not.

The development of an experimental aesthetics of food composition is here a promising line of research, though one that is still in its infancy. At this point, we want to offer some first food for thought regarding this new direction of study. First is a note of caution. Nothing proves that food composition really follows the rules of aesthetics - at least in a way that can be experimentally measured and lead to a difference in appetite, satiety or judgment. After all, there is a long tradition in aesthetics of excluding eating experiences (as well as drinking ones, see Kant [62] and Smith [63] for a discussion) because they appeal mostly to appetite and pleasure, and not to the disinterested appreciation of their visual (and nonedible) properties.

Zellner and colleagues [64] have, for instance, studied whether balance and complexity in the presentation of food on a plate would affect the attractiveness of the visual presentation. In addition, the willingness of the participants (68 undergraduates) to try the food, and their liking for it, was also measured under four different conditions of visual presentation (monochrome-balanced, coloured-balanced, monochrome-unbalanced, and coloured-unbalanced; see Figure 4). The food consisted of four slices of water chestnuts and four lines and a dot of tahini. Although the addition of colour increased the participants' rating of the attractiveness of the balanced food presentation, it had no effect on their rating of the unbalanced presentation. The participants expressed a greater willingness to try 


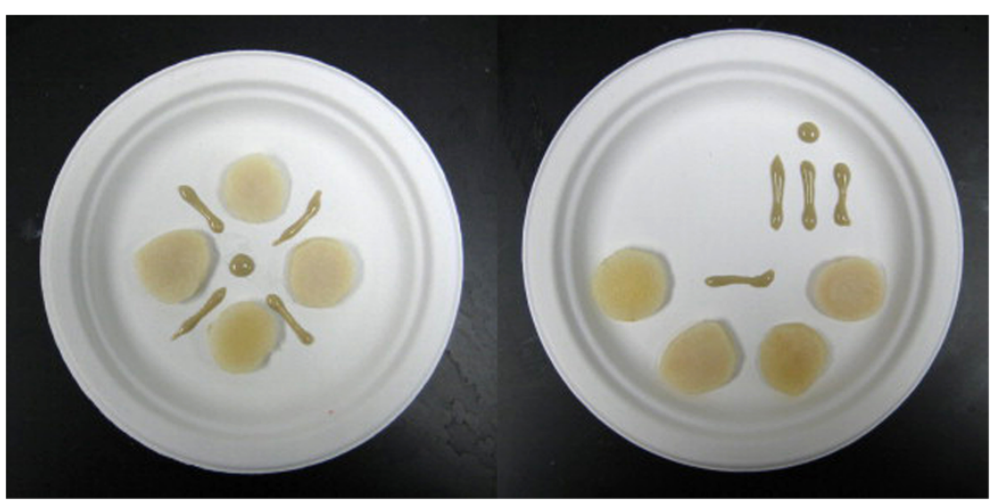

Figure 4 The balanced and unbalanced plate arrangements utilized by Zellner et al. [64]. In the coloured presentations, the lines of tahini were green and the dots were red. (Figure copyright Zellner et al. 2010 [64]).

the monochrome (plain light brown) than the colourful presentations, but there was no effect of colour or balance on people's overall liking of the flavour of the food itself. So, while manipulating the colour and balance in a dish may affect how attractive it is rated as being, Zellner et al.'s results suggest that it does not necessarily alter how much people like the flavour of the food.

However, when Zellner et al. extended this research in a subsequent study [65] with dishes composed of lettuce, carrots, tomatoes and hummus (note that the colour manipulation in their earlier study was achieved by artificially colouring the tahini), they observed that even though their participants did not report different attractiveness ratings for the two presentations (again balanced and unbalanced) as they had in the earlier study, the hummus from the more balanced presentation was liked more than that from the less balanced presentation. In a second experiment (part of the same study), these researchers found that chicken salad placed in a messy arrangement in the centre of a lettuce salad was liked more than when the chicken salad was moulded as a half sphere in the centre of the salad; consequently, Zellner and colleagues concluded that their results on participants' liking probably had more to do with the degree of neatness than with the degree of balance of the food on the plate. The connection with concerns for food purity, studied by anthropologists, might here raise an interesting set of questions, which we hope to see pursued in the near future [66].

Of course, it could be argued that complexity depends on much more than merely just the variety of colour that happens to be present in a dish. It also depends on the size of the elements, the variation in colour, the number of products, the familiarity of the person with those products, and the mix of products or elements that are involved. Mielby and colleagues examined the relationship between people's visual preferences and the perceived complexity of vegetables, fruits, and combined mixtures of fruits and vegetables [67]. Confirming previous results [68], these researchers observed strong correlations between designed collative properties and perceived complexity. Inverted U-shaped relationships between visual preference and perceived complexity were documented for both the vegetable and fruit mixes. However, no such effect was observed for the combined fruit and vegetable plates, perhaps because from the start they were already seen as being quite complex. So, the take-home message here is not to allow the visual composition of the elements to become too simple nor too complex if you want a dish to be successful (or, at least, to be visually appealing) ${ }^{\mathrm{d}}$.

The prospect of uncovering aesthetic principles of food composition should probably also look at ways in which the balance between visual elements can echo the balance between flavours, a notion also under-investigated by sensory scientists. As stressed by certain chefs, 'Culinary creation begins with taste - shape only comes as a result. Visual and taste balance are inseparable' (Philippe Jousse, former chef at Restaurant Alain Chapel, pers. comm., August 2013). And while the majority of the research (at least in recent years) has tended to focus on twodimensional representations of the visual arrangement of the food on the plate, it is worth remembering that the early work on the aesthetics of plating, for instance, by Carême and his ilk [69,70], was very much about the vertical arrangement of food. The aesthetic of plating in this respect might be closer to the aesthetics of architecture than of plating.

We would like to argue that those working in the food sector can apply theories from the psychology of aesthetics to make food products more visually appealing, thereby positively affecting a diner's food perception (and, on occasion, influencing the food choices that they make). According to Berlyne's collative motivation model [68], based on an analysis of people's responses to visual illustrations, there is a bell-shaped relationship between hedonic appreciation and the arousal potential of a given work of art or visual pattern. Collative properties such as 
complexity, novelty and variability contribute most to the arousal property of a work of art. Visual patterns with a low arousal potential - and, therefore, low levels of perceived collative properties - are simply not stimulating enough. As a consequence, they may leave the observer feeling indifferent. Patterns with very high arousal potential - and thus high levels of perceived collative properties - may be too difficult to grasp and hence considered unpleasant. The preferred patterns, then, are considered to be those with an arousal potential at a medium level, leading to the inverted U-shaped relationship between hedonic appreciation and arousal potential (see also $[71,72]$ on the dimensionality of visual complexity, interestingness and pleasantness). Another point of view suggests that people experience some kind of reward when processing visually complex stimuli [73].

At the Crossmodal Research Laboratory in Oxford, we have been investigating the impact of more complex arrangements of food. In particular, we were interested in knowing whether dishes in which the food is displayed to mimic an artist's works would be appreciated more than when the elements were arranged in a much more standard manner. Inspired by the work of Kandinsky, author and chef Charles Michel developed an edible copy of one of the artist's paintings (Painting number 201; also called Panel for Edwin R. Campbell No. 4 [74]) with vegetables, sauces and purées, served on a small canvas (Figure 5). The artistic arrangement of the elements in the dish was compared to a situation in which the very same ingredients were arranged as in a common tossed salad. In another condition, the 17 elements that went into making the salad were arranged side-by-side in a neat but non-artistic manner. The participants filled out pencil-and-paper questionnaires both before eating the food and after having finished the dish. The items in the questionnaire were designed to evaluate people's expectations and actual sensory and emotional experience of the dish. The Kandinsky-inspired artistic presentation resulted in the food being rated as more artistic (as expected). More importantly, though, the dish was significantly more liked than both of the other two presentations (a difference of around 36\%). While the participants' perceptions of the basic tastes of bitterness, sweetness, saltiness and sourness were unaffected by the plating condition, the food arranged in the art-inspired condition was rated as more than $29 \%$ tastier overall ${ }^{\mathrm{e}}$ [2]. These results suggest that, assuming that there is nothing too unpalatable on the plate when they eventually come to taste it, the diner's hedonic and sensory perception will largely be determined by the expectations that the diner has [75].

\section{Individuals around the table}

Another difficulty that awaits scientists and chefs alike in this area may come from the existence of some important

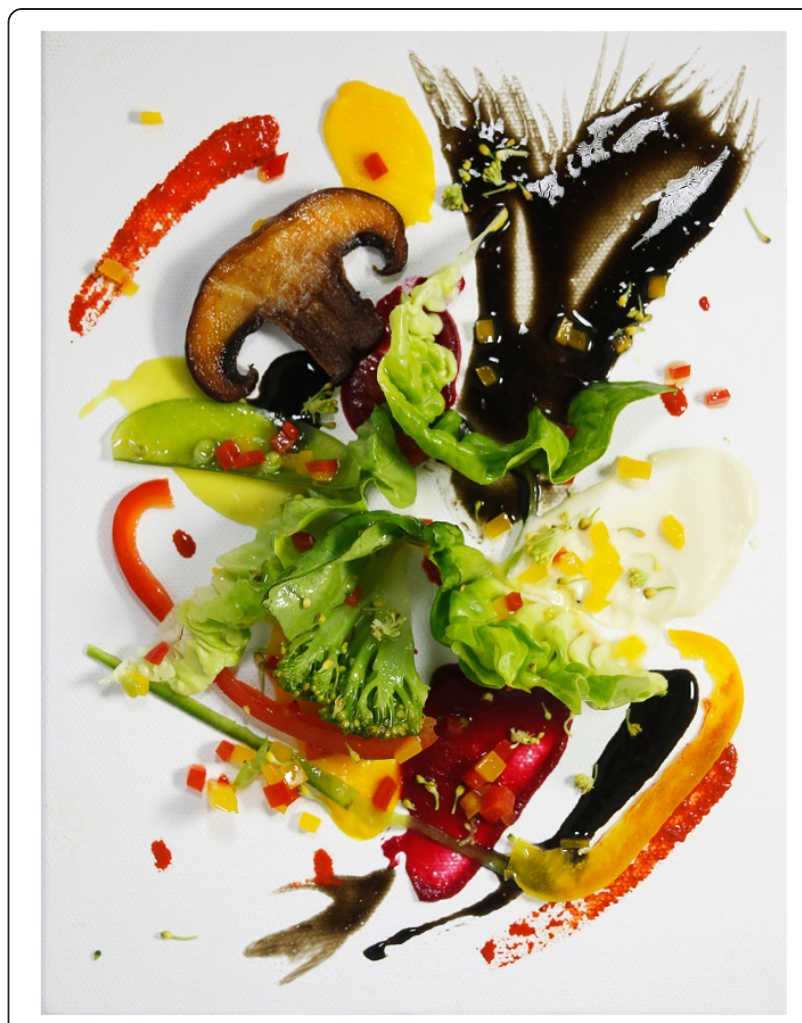

Figure $\mathbf{5}$ Salad with a taste of Kandinsky. An experimental dish arranged as one of Kandinsky's paintings. From [76]. Image credit: C. Michel and Comes Cake.

individual differences in the response of diners to various styles of plating. Two obvious factors are cross-cultural differences and individual differences in a diner's sensitivity to visual aesthetics. There would seem to be no reason, a priori, why one should expect that what looks nice to a North American diner would necessarily appeal equally to an Italian or Japanese diner. Zampollo et al. [76] recently addressed this question. The results of their intriguing research revealed that across these three countries, there were consistent preferences in terms of the number of colours on the plate (three), the number of components on the plate (three to four) and how full the plate should appear (nearly empty versus crowded, as they put it). Where cross-cultural differences were apparent was in terms of how the diners in the different countries thought the items should be organized on the plate, where the main item should appear, and the degree of casualness or organization of the presentation.

Of course, it could be that diners' responses to a plate of food depend on how sensitive they are to visual aesthetics generally. So, if these participants had been tested for this trait (using the VAST [77]; a test that is normally applied in the assessment of visual art), and the results for visual aesthetic sensitivity and flavour appreciation for artistically presented meals were found to be highly 
correlated, one might hypothesize that the visual results could extend to the sense of taste (that is, those who score more highly would likely appreciate the dish more when it is presented in a balanced manner; cross-reference [78]). Should such a correlation be found, much of the preliminary research on the design of new dishes could presumably then be conducted over the internet, perhaps using digitally modified images - a kind of virtual prototyping, but this time applied to the world of gastronomy [79-81]. Furthermore, here one perhaps also needs to consider the colour of the lighting in the restaurant. Indeed, the temperature, intensity and type of illumination can all be expected to exert some influence on the perceived colour of the plate, the food placed on it, and on the atmosphere, and hence on the flavour of the food itself, not to mention on the mood of the guests.

The sensory dimensions of the plate might be the central part of our experience of eating (and the main focus of our attention), but it is certainly not the only one. Concentric to the dish, how the table is arranged can be considered as a wider frame for the plate. In addition, food rarely comes to the table without a simultaneous verbal description, often orientating and biasing the diner's perception. Then the atmospherics surrounding the table (and its many variables), and the social context all play a role on our behaviours, and how enjoyable and healthy the food finally is.

\section{Conclusions}

Although the deliciousness and healthiness of foods depend substantially on the skilled palates, sensitivity and responsibility of the individuals delivering them, the results of the various research studies that have been reviewed here clearly demonstrate that the plateware can contribute to the diners' health and overall multisensory eating experience.

Both the interactions between presentation and dishes, and how these elements combine with the rest of the restaurant environment are topics that are rapidly becoming better understood, and are certainly fascinating to study. Further investigation may try to understand how our attention is modulated depending on the food display, getting to know more about the eye's path through the dish, and how that influences the flavour journey the diner will travel could certainly open up new creative processes in the chef's mind. A better understanding of the relationship between the aesthetic of food displays and the main principles of harmony in art could also give light to exciting new approaches.

As was stressed in the first part of the manifesto, the aestheticization of food and eating experiences develops out of a concern for finer combinations of flavours. Certainly, in the quest for those finer recipes, the eye can, as much as the palate, suggest new associations.

\section{Endnotes}

${ }^{\mathrm{a}} \mathrm{Here}$, of course, one might also wonder what happens when the diner does not manage to finish all their food. Is the amount of waste also correlated positively with the size of the plate?

${ }^{\mathrm{b}}$ It is important to underscore the fact that the texture and material from which the plate is made may also exert an influence on the visual appearance of the overall dish: a textured plate (incorporating shading and distinctive shapes) may give rise to more complex patterns of colours. Different materials and coatings (for example, shiny versus matt) might also be expected to change certain characteristics of the colour. Controlling for these additional aspects is certainly a challenge for the comparability and generalization of the few scientific studies that have now started to appear where the differences induced by changing the colour of the plate or container in which the same food or dish is presented have been studied.

${ }^{c}$ Potentially worrying here is the observation that those patients who require special nutritional attention in UK hospitals are normally given their meals from a red tray so that the nurses and health assistants can easily identify them [82]. We are unaware of whether anyone has actually studied the effect that being served food from a red tray may have on patients' eating behaviours (see [83] for the negative consequences of red on people's eating behaviours). Certainly, choosing the colour of a patient's dish and tray is a decision that really ought not to be left to chance.

${ }^{\mathrm{d}}$ Of course, the degree of complexity that is acceptable in a dish may vary depending on the context in which it is served (for example, the mess canteen versus a Michelin-starred restaurant).

${ }^{\mathrm{e}}$ It is also important to note that mixed culinary elements on a plate can merge to create new flavours. In this sense, the way in which a dish can be arranged may, in fact, lead them to have different flavours (physically - as opposed to any effect that they have due to the psychological impact the different display can have).

\section{Competing interests}

The authors declare that they have no competing interests.

\section{Authors' contributions}

All of the authors contributed to the writing of this manuscript. All authors read and approved the final manuscript.

Authors' information

CM is Chef in residence at the Crossmodal Research Laboratory.

\section{Acknowledgements}

CS and OD were funded by an AHRC grant in the 'Science in Culture' programme.

\section{Author details}

${ }^{1}$ Crossmodal Research Laboratory, Department of Experimental Psychology,

University of Oxford, South Parks Road, Oxford OX1 3UD, England, UK.

${ }^{2}$ Centre for the Study of the Senses, Institute of Philosophy, University of London, London, UK. 
Received: 29 December 2013 Accepted: 24 January 2014

Published: 20 May 2014

\section{References}

1. Escoffier A: Le Guide Culinaire. 1st edition. Paris: Gallimard; 1902.

2. Van der Laan LN, de Ridder DTD, Viergever MA, Smeets PA: The first taste is always with the eyes: a meta-analysis on the neural correlates of processing visual food cues. Neuroimage 2011, 55:296-303.

3. Drobes DJ, Miller EJ, Hillman CH, Bradley MM, Cuthbert BN, Lang PJ: Food deprivation and emotional reactions to food cues: implications for eating disorders. Biol Psychol 2001, 57:153-177.

4. Spence C: Mouth-watering: the influence of environmental and cognitive factors on salivation and gustatory/flavour perception. J Texture Stud 2011, 42:157-171.

5. Wallner-Liebmann $\mathrm{S}$, Koschutnig K, Reishofer G, Sorantin E, Blaschitz B, Kruschitz R, Unterrainer HF, Gasser R, Freytag F, Bauer-Denk C, Mangge H: Insulin and hippocampus activation in response to images of high-calorie food in normal weight and obese adolescents. Obesity 2010, 18:1552-1557.

6. Ouwehand C, Papies EK: Eat it or beat it. The differential effects of food temptations on overweight and normal-weight restrained eaters. Appetite 2010, 55:56-60.

7. Berthoud HR, Morrison C: The brain, appetite, and obesity. Annu Rev Psychol 2008, 59:55-92.

8. Shin AC, Zheng $H$, Berthoud HR: An expanded view of energy homeostasis: neural integration of metabolic, cognitive, and emotional drives to eat. Physiol Behav 2009, 97:572-580.

9. Levitsky D, Youn $\mathrm{T}$ : The more food young adults are served, the more they overeat. J Nutr 2004, 134:2546-2549.

10. Wansink B: From mindless eating to mindlessly eating better. Physio Behav 2010, 100:454-463.

11. Nielsen SJ, Popkin BM: Patterns and trends in portion size. J Am Med Assoc 2003, 289:450-453.

12. Wansink B, van Ittersum $K$, Painter JE: Ice cream illusions: bowl size, spoon size, and self-served portion sizes. Am J Prev Med 2006, 31:240-243.

13. Diliberti N, Bordi PL, Conklin MT, Roe LS, Rolls BJ: Increased portion size leads to increased energy intake in a restaurant meal. Obes Res 2004, 12:562-568.

14. Wansink B, Cheney MM: Super bowls: serving bowl size and food consumption. J Am Med Assoc 2005, 293:1727-1728.

15. Van Kleef E, Shimizu M, Wansink B: Serving bowl selection biases the amount of food served. J Nutr Educ Behav 2012, 44:66-70.

16. Lyman B: A Psychology of food, more than a matter of taste. New York: Van Nostrand Reinhold; 1989.

17. Titchener EB: Lectures on the Elementary Psychology of Feeling and Attention New York: Macmillan; 1908.

18. Rolls BJ, Roe LS, Halverson $\mathrm{KH}$, Meengs JS: Using a smaller plate did not reduce energy intake at meals. Appetite 2007, 49:652-660.

19. Piqueras-Fiszman B, Giboreau A, Spence C: Assessing the influence of the color of the plate on the perception of a complex food in a restaurant setting. Flavour 2013, 2:24.

20. de Graaf C, Cardello AV, Kramer FM, Lesher LL, Meiselman HL, Schutz HG: A comparison between liking ratings obtained under laboratory and field conditions: the role of choice. Appetite 2005, 44:15-22.

21. Rozin P, Kabnick K, Pete E, Fischler C, Shields C: The ecology of eating: smaller portion sizes in France than in the United States help explain the French paradox. Psychol Sci 2003, 14:450-454.

22. Kral TV: Effects on hunger and satiety, perceived portion size and pleasantness of taste of varying the portion size of foods: a brief review of selected studies. Appetite 2006, 46:103-105

23. Restaurante Denis Martin. [http://www.denismartin.ch/]

24. Deroy O, Piqueras-Fiszman B, Michel C, Spence C: The plating manifesto (I): from decoration to creation.

25. Yang J: The art of food presentation. 2011. [http://www.cravemag.com/ features/the-art-of-food-presentation/]

26. 10 colors that increase and decrease your appetite. [http://weightloss allwomenstalk.com/colors-that-decrease-and-increase-your-appetite]

27. Harrar $V$, Piqueras-Fiszman B, Spence C: There's more to taste in a coloured bowl. Perception 2011, 40:880-882.

28. Piqueras-Fiszman B, Alcaide J, Roura E, Spence C: Is it the plate or is it the food? The influence of the color and shape of the plate on the perception of the food placed on it. Food Qual Prefer 2012, 24:205-208.
29. Shankar MU, Levitan CA, Spence C: Grape expectations: the role of cognitive influences in color-flavor interactions. Conscious Cogn 2010, 19:380-390.

30. Ekroll V, Faul F, Niederée R: The peculiar nature of simultaneous colour contrast in uniform surrounds. Vis Res 2004, 44:1765-1786.

31. Hutchings JB: Food Colour and Appearance. London: Blackie Academic and Professional; 1994

32. Leibowitz $H$, Myers NA, Chinetti $P$ : The role of simultaneous contrast in brightness constancy. J Exp Psychol 1955, 50:15-18.

33. Blackwell L: Visual cues and their effects on odour assessment. Nutr Food Sci Nutr 1995, 95(5):24-28.

34. Spence C, Levitan C, Shankar MU, Zampini M: Does food color influence taste and flavor perception in humans? Chemosens Percept 2010, 3:68-84

35. Harrar V, Spence C: The taste of cutlery. Flavour 2013, 2:21.

36. Maga JA: Influence of color on taste thresholds. Chem Senses 1974, 1:115-119.

37. O'Mahony M: Gustatory responses to nongustatory stimuli. Perception 1983, 12:627-633.

38. Piqueras-Fiszman B, Spence C: Crossmodal correspondences in product packaging: assessing color-flavor correspondences for potato chips (crisps). Appetite 2011, 57:753-757.

39. Spence C, Piqueras-Fiszman B: The multisensory packaging of beverages. In Food Packaging: Procedures, Management and Trends. Edited by Kontominas MG. New York: Nova Publishers, Hauppauge; 2012:187-233.

40. Asch SE: Forming impressions of personality. J Abnorm Soc Psychol 1946, 41:258-290

41. Churchill A, Meyners M, Griffiths L, Bailey P: The cross-modal effect of fragrance in shampoo: modifying the perceived feel of both product and hair during and after washing. Food Qual Prefer 2009, 20:320-328.

42. Gal D, Wheeler SC, Shiv B: Cross-modal influences on gustatory perception; 2007. [http://ssrn.com/abstract=1030197]

43. Deroy $O$, Valentin D: Tasting liquid shapes: investigating the sensory basis of cross-modal correspondences. Chemosens Percept 2011, 4:80-90.

44. Day SA: The human sensoria and synaesthetic approach to cooking. Collapse 2011, 7:378-409

45. Spence C, Deroy O: Tasting shapes: a review of four hypotheses. Theoria et Historia Scientiarum in press.

46. Deroy $\mathrm{O}$, Spence C: Quand les gouts \& les formes se répondent. Cerveau Psycho 2013, 55:74-79.

47. Spence C: Managing sensory expectations concerning products and brands: capitalizing on the potential of sound and shape symbolism. J Consum Psychol 2012, 22:37-54.

48. Williams JM: Synesthetic adjectives: a possible law of semantic change. Language 1976, 52:461-478.

49. Spence C, Ngo M, Percival B, Smith B: Crossmodal correspondences: assessing the shape symbolism of foods having a complex flavour profile. Food Qual Prefer 2013, 28:206-212.

50. Apicius: Cooking and Dining in Imperial Rome (c. 1st Century; translated by J. D. Vehling). Chicago: University of Chicago Press; 1936:103.

51. Luki Huber, plateware designer for elBulli. [http://www.lukihuber.com/]

52. Piqueras-Fiszman B, Spence C: The weight of the bottle as a possible extrinsic cue with which to estimate the price (and quality) of the wine? Observed correlations. Food Qual Prefer 2012, 25:41-45.

53. Spence C, Piqueras-Fiszman B: Multisensory design: weight and multisensory product perception. In Proceedings of Right Weight. Volume 2. Edited by Hollington G. London: Materials KTN; 2011:8-18.

54. Lakoff G, Johnson M: Metaphors We Live By. Chicago: Chicago University Press; 1983.

55. Stewart PC, Goss E: Plate shape and colour interact to influence taste and quality judgments. Flavour 2013, 2:27.

56. Gallace A, Spence C: In Touch with the Future: the sense of touch from cognitive neuroscience to virtual reality. Oxford: Oxford University Press; 2014.

57. Meiselman HL: Dimensions of the Meal: The Science, Culture, Business, and Art of Eating. Gaithersburg, MA: Aspen Publishers; 2000.

58. Reisfelt HH, Gabrielsen G, Aaslyng MD, Bjerre MS, Møller P: Consumer preferences for visually presented meals. J Sens Stud 2009, 24:182-203.

59. Arnheim R: The Power of the Center: A Study of Composition in the Visual Arts. Berkeley, CA: University of California Press; 1988.

60. Bouleau C: The Painter's Secret Geometry. New York: Hacker Books; 1980

61. Wilson A, Chatterjee A: The assessment of preference for balance: introducing a new test. Empir Stud Arts 2005, 23:165-180.

62. Kant E: In Critique of the Power of Judgement. Edited by Guyer P. Cambridge: Cambridge University Press; 2000 
63. Smith BC: The aesthetics of wine. In Oxford Companion to Aesthetics. Edited by Keeley B. Oxford: Oxford University Press. in press.

64. Zellner DA, Lankford M, Ambrose L, Locher P: Art on the plate: effect of balance and color on attractiveness of, willingness to try and liking for food. Food Qual Prefer 2010, 21:575-578.

65. Zellner DA, Siemers E, Teran V, Conroy R, Lankford M, Agrafiotis A, Ambrose L, Locher P: Neatness counts. How plating affects liking for the taste of food. Appetite 2011, 57:642-648.

66. Douglas M: Purity and Danger: an Analysis of Concepts of Pollution and Taboo. London: Routledge and Kegan Paul; 1966.

67. Mielby LH, Kildegaard H, Gabrielsen G, Edelenbos M, Thybo AK: Adolescent and adult visual preferences for pictures of fruit and vegetable mixes effect of complexity. Food Qual Prefer 2012, 26:188-195.

68. Berlyne DE: Novelty, complexity and hedonic value. Percept Psychophys 1970, 8:279-286.

69. Carême MA: Le Pâtissier Pittoresque, Précédé d'un Traité des Cinq Ordres $d^{\prime}$ Architecture [The picturesque pastry chef, preceded by a treatise of the five orders of architecture]. Paris: Reanouard; 1828.

70. Horowitz J, Singley P: Eating Architecture. Cambridge, MA: MIT Press; 2004.

71. Hekkert P, Leder H: Design aesthetics. In Product Experience. Edited by Schifferstein HNJ, Hekkert P. London: Elsevier; 2008:259-285.

72. Berlyne DE, Ogilve JC, Parham LCC: The dimensionality of visual complexity, interestingness, and pleasingness. Can J Psychol 1968, 22:376-387.

73. Ramachandran VS: The Emerging Mind. London: Profile Books; 2003.

74. Painting \#201 by Kandinsky, Moma Museum website. [http://www.moma. org/collection/provenance/provenance_object.php?object_id=79452]

75. Michel C, Gatti E, Velasco C, Spence C: A taste of Kandinsky: Enhancing expectations and experience through the use of art-inspired food presentation, Poster presentation given at the $10^{\text {th }}$ Pangborn Sensory Science Symposium (11-15 th August 2013, Rio de Janeiro, Brazil); 2013.

76. Zampollo F, Wansink B, Kniffin KM, Shimuzu M, Omori A: Looks good enough to eat: how food plating preferences differ across cultures and continents. Cross Cult Res 2012, 46:31-49.

77. Goetz KO, Borisy AR, Lynn R, Eysenck HJ: A new visual aesthetic sensitivity test: I. Construction and psychometric properties. Percept Mot Skills 1979, 49:795-802.

78. Becker L, van Rompay TJL, Schifferstein HNJ, Galetzka M: Tough package, strong taste: the influence of packaging design on taste impressions and product evaluations. Food Qual Prefer 2011, 22:17-23.

79. Kildegaard H, Olsen A, Gabrielsen G, Møller P, Thybo AK: A method to measure the effect of food appearance factors on children's visual preferences. Food Qual Prefer 2011, 22:763-771.

80. Spence C, Piqueras-Fiszman B: The Perfect Meal: The Multisensory Science of Food and Dining. Oxford: Wiley-Blackwell. in press.

81. Wei ST, Ou LC, Luo MR, Hutchings JB: Optimization of food expectations using product colour and appearance. Food Qual Prefer 2012, 23:49-62.

82. Bradley L, Rees C: Reducing nutritional risk in hospital: the red tray. Nurs Stand 2003, 17:33-37.

83. Genschow $\mathrm{O}$, Reutner $L$, Wänke M: The color red reduces snack food and soft drink intake. Appetite 2012, 58:699-702.

\section{Submit your next manuscript to BioMed Central and take full advantage of:}

- Convenient online submission

- Thorough peer review

- No space constraints or color figure charges

- Immediate publication on acceptance

- Inclusion in PubMed, CAS, Scopus and Google Scholar

- Research which is freely available for redistribution

Submit your manuscript at www.biomedcentral.com/submit
Ciomed Central 